\title{
An improved in-vitro model for the study of gonadotrophin secretion from immature rat pituitaries
}

\author{
Y. Koch, R. Meidan, P. Chobsieng and Z. Naor \\ Department of Hormone Research, Weizmann Institute of Science, Rehovot, Israel
}

Studies on the regulation of release of the gonadotrophic hormones from the anterior pituitary have in general utilized incubations of hemipituitaries derived from adult male rats (Wakabayashi, Date \& Tamaoki, 1973). The small magnitude of stimulation (2-3-fold) of hormonal release by gonadotrophin-releasing hormone ( $\mathrm{GnRH})$ has led investigators to search for a more sensitive model using pituitaries from pro-oestrous rats (Ferland et al., 1975) and anterior pituitary monolayer cultures (Tang \& Spies, 1975) or dispersed cells (Nakano, Fawcett \& McCann, 1976). The present report describes a simple and sensitive model for the study of gonadotrophic hormone release.

Pituitaries were taken from 12-day- and 2-month-old male and female Wistar-derived rats. Each pituitary was placed in $1 \mathrm{ml} \mathrm{Krebs-Ringer} \mathrm{bicarbonate} \mathrm{buffer} \mathrm{(KRB)} \mathrm{pH} 7 \cdot 4$, containing glucose $(1 \mathrm{mg} / \mathrm{ml})$, and initially incubated for $2 \mathrm{~h}$ at $37^{\circ} \mathrm{C}$ under an atmosphere of $95 \% \mathrm{O}_{2}: 5 \% \mathrm{CO}_{2}$. The medium was then changed to $1 \mathrm{ml} \mathrm{KRB}$ or $1 \mathrm{ml} \mathrm{KRB}$ containing GnRH (Hoechst) and incubation was continued for the time indicated. At the end of the incubation period, aliquots of the medium were analysed for LH and FSH content by radioimmunoassay (Daane \& Parlow, 1971) using the kits kindly supplied by the NIAMDD, Rat Pituitary Hormone Program, NIH, Bethesda, U.S.A. Results are expressed in terms of the RP-1 reference preparations. The sensitivity of the assays was $10 \mathrm{ng} / \mathrm{ml}$ and $50 \mathrm{ng} / \mathrm{ml}$ for $\mathrm{LH}$ and FSH, respectively. The inter-assay coefficient of variation was $5 \%$.

Table 1. Effect (as \% of control) of increasing doses of GnRH on FSH and LH release from pituitaries of immature and adult rats during a $4-\mathrm{h}$ incubation

\begin{tabular}{lcccccc}
\hline & \multicolumn{3}{c}{ FSH } & \multicolumn{3}{c}{ LH } \\
\cline { 2 - 7 } & \multicolumn{5}{c}{ GnRH } & $\left(10^{-9} \mathrm{M}\right)$ \\
\cline { 2 - 7 } Pituitary donor & $0 \cdot 25$ & $1 \cdot 0$ & $5 \cdot 0$ & $0 \cdot 25$ & $1 \cdot 0$ & $5 \cdot 0$ \\
\hline Immature females & $120 \pm 18$ & $325 \pm 44^{* *}$ & $760 \pm 40^{* *}$ & $220 \pm 20^{* *}$ & $550 \pm 80^{* *}$ & $980 \pm 40^{* *}$ \\
Immature males & $180 \pm 20^{* *}$ & $300 \pm 32^{* *}$ & $600 \pm 60^{* *}$ & $180 \pm 20^{* *}$ & $585 \pm 62^{* *}$ & $940 \pm 80^{* *}$ \\
Pro-oestrous females & $131 \pm 25$ & $175 \pm 28^{*}$ & $310 \pm 23^{* *}$ & $210 \pm 15^{* *}$ & $340 \pm 40^{* *}$ & $785 \pm 60^{* *}$ \\
Adult males & $90 \pm 15$ & $130 \pm 17$ & $160 \pm 30^{*}$ & $180 \pm 10^{* *}$ & $310 \pm 35^{* *}$ & $346 \pm 51^{* *}$ \\
\hline
\end{tabular}

Values are mean \pm S.E.M. for 12 determinations. Means were compared with control values by Student's $t$ test. $* P<0.02 ; * * P<0.001$.

Incubation of pituitaries with increasing concentrations of GnRH for $4 \mathrm{~h}$ resulted in a doserelated increase in the release of LH and FSH. The stimulation of LH and FSH release was more pronounced when pituitary donors were immature rather than adult rats (Table 1). The kinetics of gonadotrophin release were studied by incubating pituitaries with $5 \mathrm{~nm}$ (mature rats) or $1 \mathrm{nM}$ (immature rats) GnRH for various periods (Text-fig. 1). A significant stimulation of LH release by GnRH occurred from adult pituitaries after $90 \mathrm{~min}$ of incubation, whereas enhanced gonadotrophin release from immature pituitaries was evident even after $20 \mathrm{~min}$. The maximal relative increase of $\mathrm{LH}$ (8-fold) and FSH (3-fold) release from pituitaries of adult rats was observed in pro-oestrous females after $4 \mathrm{~h}$ of incubation with $\mathrm{GnRH}$, whereas a more marked stimulation of gonadotrophin secretion (LH, 33-fold; FSH, 5-5-fold) was observed in pituitaries of immature females after 90 min of incubation. The absolute increment of $\mathrm{LH}$ in the immature rat was similar to that seen in the adult, even 


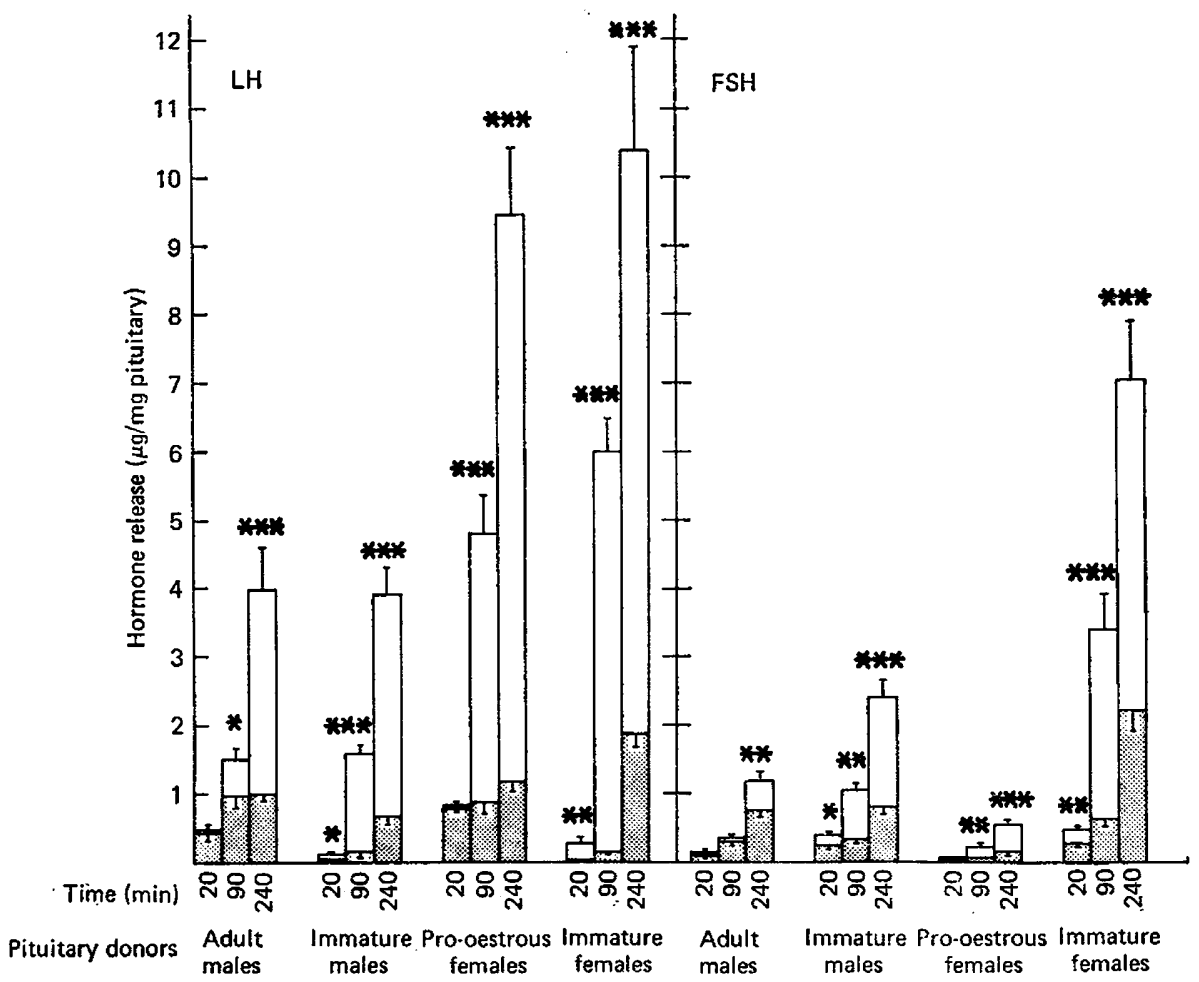

Text-fig. 1. Effect of GnRH (open columns) on LH and FSH release from pituitary glands of immature and adult female and male rats. Concentration of GnRH: $1 \times 10^{-9} \mathrm{M}$ for the immature rats and $5 \times 10^{-9} \mathrm{M}$ for the mature rats. Stippled columns represent control incubations. Vertical bars indicate S.E.M. for 18 determinations; means were compared with control values by Student's $t$ test. ${ }^{*} P<0.05 ;{ }^{* *} P<0.01$; *** $P<0.001$.

though a lower dose of GnRH ( $1 \mathrm{~nm}$ compared to $5 \mathrm{~nm}$ ) was used, whereas the absolute increment of FSH was greater in the immature animal.

Pituitaries derived from immature rats provide an improved model for the study of gonadotrophin release because they respond to low doses of GnRH after a short period of incubation with an augmented stimulation of $\mathrm{LH}$ and FSH release.

Supported by the Ford Foundation and the Population Council, Inc., N.Y.

\section{References}

DaAne, T.A. \& Parlow, A.F. (1971) Periovulatory patterns of rat serum follicle stimulating hormone and luteinizing hormone during the estrous cycle: effects of pentobarbital. Endocrinology 88, 653663.

Ferland, L., Borgeat, P., Labrie, F., Bernard, J., De-Lean, A. \& RaYnaud, J.P. (1975) Changes of pituitary sensitivity to LHRH during the rat estrous cycle. Molec. Cell Endocr. 2, 107-115.

Nakano, H., Fawcett, C.P. \& McCann, S.M. (1976) Enzymatic dissociation and short term culture of isolated rat anterior pituitary cells for studies on the control of hormone secretion. Endocrinology 98, 278-288.

TANG, L.H. \& SPIEs, H.G. (1975) Effects of gonadal steroids on the basal and LRF-induced gonadotrophin secretion by cultures of rat pituitary. Endocrinology 96, 349-356.

Wakabayashi, K., Date, Y. \& Tamaoki, B. (1973) On the mechanism of action of luteinizing hormone releasing factor and prolactin release inhibiting factor. Endocrinology 92, 698-704. 